\title{
Investigating the Seroprevalence of Hepatitis E Among Blood Donors Referring to Blood Donation Centers in Birjand County in Iran
}

\author{
Zohreh Azarkar, ${ }^{1, *}$ Mohammad Reza Miri, ${ }^{2}$ and Shima Arjmand ${ }^{3}$ \\ ${ }^{1}$ Infectious Diseases Research Center, Birjand University of Medical Sciences, Birjand, Iran \\ ${ }^{2}$ Social Determinant of Health Research Center, Birjand University of Medical Sciences, Birjand, Iran \\ ${ }^{3}$ MD Student, Committee Research Center, Birjand University of Medical Sciences, Birjand, Iran \\ "Corresponding author: Zohreh Azarkar, Associated Professor of Infectious Diseases, Infectious Diseases Research Center, Birjand University of Medical Sciences, Birjand, Iran. \\ Tel: +98-564443000, E-mail: drz.azarkar@yahoo.com
}

Received 2015 July 12; Revised 2015 December 08; Accepted 2015 December 14.

\begin{abstract}
Background: Hepatitis $\mathrm{E}$ is among the most important health challenges in many countries. This study aimed at investigating the sero-prevalence of hepatitis E among blood donors in Birjand county, Iran.

Methods: This cross-sectional descriptive-analytical study was performed in 2013 - 2014 on 340 blood donors who referred to blood donation centers in Birjand county, Iran, for blood donation. The participants were recruited through simple random sampling. A researcher-made questionnaire was used for data collection which included items such as demographic characteristics, past medical history, history of blood transfusion, and the source of drinking water. The validity of the questionnaire was confirmed by an infectious disease specialist and a statistician. A five-milliliter blood sample was obtained from each donor and serological assessment was performed for detecting hepatitis E virus antibody by using the ELISA method. The data were analyzed through running logistic regression analysis using the SPSS software (version 15.0).

Results: From 340 participants, 319 cases (93.8\%) were male, 256 cases (75.3\%) held university degrees, 13 cases (3.8\%) had a history of blood transfusion, and 50 cases (14.7\%) were anti-hepatitis E positive. The result of serologic test was significantly correlated with the participants' educational status, place of residence, and source of drinking water $(\mathrm{P}<0.05)$. However, the correlation of the test result with the participants' gender, age, employment, and history of blood transfusion was not statistically significant.

Conclusions: The prevalence of hepatitis $\mathrm{E}$ in the present study was higher than previous studies, denoting the higher prevalence of hepatitis $\mathrm{E}$ in the area. Moreover, the prevalence of hepatitis $\mathrm{E}$ is lower among blood donors who have higher educational status, live in urban areas, and use piped water.
\end{abstract}

Keywords: Hepatitis E, Sero-Prevalence, Blood Donor

\section{Background}

Hepatitis E is a viral infection which spreads through the fecal-oral route. It is caused by an RNA virus that is a member of the hepatoviridae family and is transmitted through contaminated water and foods (1). Hepatitis E is an acute and self-limiting hepatitis which happens either as an epidemic or sporadic infection. In most cases, hepatitis E may be associated with no clinical manifestation; nonetheless, in some cases, it may become a fulminant and lethal disease. Like other types of hepatitis, symptomatic hepatitis $\mathrm{E}$ is manifested by jaundice (2).

In Asia, hepatitis E virus (HEV) is the main cause of acute hepatitis among adults while in the Middle East, it is the second cause of acute adult hepatitis only after hepatitis B virus (1). Despite many reports on the high prevalence of hepatitis E in Asia, Africa, and Central America, there is limited data on the epidemiology of the disease in Iran (3). Between 1990 to1991, hepatitis E was the first emergent epidemic in Kermanshah, Iran (2). Sero-epidemiological stud- ies show that the prevalence of hepatitis $\mathrm{E}$ in developing countries is $10 \%-35 \%$ (4).

The most important complication of hepatitis E is severe fulminant lethal hepatitis among pregnant women and patients with chronic liver disease (5). In developing countries, this infection usually spreads through the fecaloral route and via contaminated water. Other routes of HEV transmission, particularly in areas where the infection is endemic, are mother-to-child, dialysis, and blood transfusion. HEV transmission through blood transfusion is very rare and has been reported in some developed countries (6).

One of the main concerns of blood banks throughout the world is to procure healthy blood and blood products. Due to some reports on HEV transmission through blood transfusion, this type of HEV transmission is considered as a big threat to blood products and a matter of great concern (7).

Based on the results of previous studies, Iran may be considered as an endemic area for hepatitis E (2-5). How- 
ever, there are limited data on the sero-prevalence of hepatitis $\mathrm{E}$ among Iranian blood donors, particularly in eastern regions of Iran. Consequently, this study was made to investigate the sero-prevalence of hepatitis E among blood donors in Birjand county, Iran.

\section{Methods}

This cross-sectional descriptive-analytical study was performed from 2013to 2014. A random sample of 340 blood donors who referred to blood donation centers in Birjand county, Iran, for blood donation were recruited through simple random sampling. Sample size was calculated by using the findings of a study made by Mohebi et al. (2012), a p of 10\%, and a d of 0.03 and by using the following sample size formula:

Equation 1.

$n=\frac{Z^{2} p q}{d^{2}}$

Mohebi et al. (2012) had reported that the prevalence of hepatitis $E$ in people aged less than 30 was $9.6 \%$ (8).

A researcher-made questionnaire was used for data collection. The questionnaire included items such as demographic characteristics, past medical history, history of blood transfusion, and the source of drinking water. The validity of the questionnaire was confirmed by two faculty members. After securing written consent, a five-milliliter intravenous blood sample was obtained from each participant and the serum was separated. The samples were kept in the blood donation laboratory of Birjand county at a temperature of $-20^{\circ} \mathrm{C}$. After obtaining samples from all 340 participants, anti-HEVtest was performed by a laboratory technician] using the ELISA method and the DIAPRO kit.

The data were analyzed using the SPSS software (version 15.0) and by running logistic regression analysis at a significance level of less than 0.05 .

\section{Results}

From 340 participating blood donors, 319 cases (93.8\%) were male, 254 cases $(74.8 \%$ ) aged 20 - 40, 200 cases $(58.8 \%)$ were white-collar workers, 270 cases $(79.4 \%$ ) lived in urban areas, 256 cases $(75.3 \%$ ) had university degrees, 280 cases (82.4\%) used piped water, and 13 cases (3.8\%) had a history of blood transfusion. The results of serological tests revealed that 50 participants (14.7\%) were anti-HEV positive (Table 1).

The results of logistic regression analysis illustrated that affliction by hepatitis E was significantly correlated with the participants' educational status, place of residence, and source of drinking water $(\mathrm{P}<0.05)$. The chance of developing hepatitis $\mathrm{E}$ among participants with diploma and below-diploma degrees was 3.20 times more than participants with university degrees. Moreover, those participants who lived in rural areas were 3.56 times more likely to develop the infection compared with the participants who lived in urban areas. Finally, the chance of developing the infection among those participants who supply their drinking water from wells or ancient aqueducts was 4.17 times more than those who used piped water (Table 1).

\section{Discussion}

Hepatitis $\mathrm{E}$ is the cause for $50 \%$ of all cases of acute hepatitis and is a serious threat to public health. Studies have reported different prevalence rates for this infection. Moreover, studies conducted in Iran showed that Iran might be an endemic area for this infection. Our findings showed that the relative frequency of blood donors who were anti-HEV positive was 14.7, which is greater than the relative frequency reported in other areas of Iran. For instance, the results of a community-based study by Taremi et al. (2008) in Nahavand, Iran, showed that the seroprevalence of hepatitis $\mathrm{E}$ among healthy people was 9.6\% (9). Moreover, the results of two studies in Mazandaran, Iran, showed that the prevalence of the disease among individuals who aged less than ten, aged 20 - 25, and older adults was respectively 1.1\%, 7.2\% (10), and 11.8\% (11). Furthermore, Aminiafshar et al. (2004) found that the prevalence of the disease in Isfahan, Tehran, Kermanshah, and Sari Iran, was 3.8\%, 9.3\%, 7.7\%, and 2.3\%, respectively (12). Studies on Iranian blood donors also showed varying prevalence rates for hepatitis E. For instance, the prevalence of the infection among blood donors in Hamedan, Tabriz, Khouzestan, and Tehran Iran, has been reported to be $12.9 \%$ (13), $7.8 \%(14), 11.5 \%$ (15), $7.8 \%$ and $4.5 \%(12,16)$, respectively. These findings show that the prevalence of hepatitis $E$ among the general population of Iran ranges from 3.8\% to 11.8\%, which is less than the prevalence found in the present study.

The sero-prevalence of the infection in developing countries with poor sanitation as well as in developed countries has been reported to be respectively higher and lower than Iran (17-19). Abe et al. (2006) reported that the sero-prevalence of hepatitis $\mathrm{E}$ in Europe, Brazil, Japan, China, and the Middle East is respectively $0.95 \%-20.6 \%$, $2.3 \%, 3.7 \%, 32.6 \%$, and $4 \%-5.2 \%$ (20). Moreover, the results of a study on blood donors in industrial countries namely United States, England, France, Germany, Spain, and Italy illustrated anti-HEV sero-positivity rates of 1.2\% - 2.2\% (20). The prevalence of hepatitis $E$ in neighboring countries of Iran including Turkey, Kurdistan of Iraq, and Pakistan has been also reported to be respectively 3.8\% (21), 14.8\% (22), and $17.5 \%$ (22). The prevalence of the infection among blood donors in Saudi Arabia has been as high as 33.3\% (23). 
Table 1. The Risk Factors for Developing Hepatitis E Among the Participants

\begin{tabular}{|c|c|c|c|c|}
\hline Risk Factors & $\mathbf{N}(\%)$ & Affliction by HEV, N (\%) & OR (CI 95\%) & P Value \\
\hline \multicolumn{5}{|l|}{ Gender } \\
\hline Male & $319(93.8)$ & $48(15)$ & 1 & \\
\hline Female & $21(6.2)$ & $2(9.5)$ & $0.59(0.13-2.63)$ & 0.49 \\
\hline \multicolumn{5}{|l|}{ Education } \\
\hline University & $256(75.3)$ & $27(10.5)$ & 1 & \\
\hline$\leq$ Diploma & $84(24.7)$ & $23(27.4)$ & $3.20(1.71-5.97)$ & $<0.001$ \\
\hline \multicolumn{5}{|l|}{ Age } \\
\hline$\leq 20$ & $17(5)$ & $3(17.6)$ & 1 & \\
\hline $20-40$ & $254(74.7)$ & $29(11.4)$ & $0.60(0.16-2.22)$ & 0.45 \\
\hline $40<$ & $69(20.3)$ & $18(26.1)$ & $1.65(0.42-6.40)$ & 0.47 \\
\hline \multicolumn{5}{|l|}{ Employment } \\
\hline Self-employed & $105(30.8)$ & $14(13.3)$ & 1 & \\
\hline Farmer or worker & $20(5.9)$ & $5(25)$ & $2.17(0.68-6.90)$ & 0.19 \\
\hline White-collar worker & $200(58.8)$ & $27(13.5)$ & $1.01(0.51-2.03)$ & 0.97 \\
\hline Unemployed & $15(4.5)$ & $4(26.7)$ & $2.36(0.66-8.46)$ & 0.19 \\
\hline \multicolumn{5}{|l|}{ Place of residence } \\
\hline Urban & $270(79.4)$ & $29(10.7)$ & 1 & \\
\hline Rural & $70(20.6)$ & $21(30)$ & $3.56(1.88-6.76)$ & $<0.001$ \\
\hline \multicolumn{5}{|l|}{ History of blood transfusion } \\
\hline Yes & $13(3.8)$ & $2(15.4)$ & 1 & \\
\hline No & $327(96.2)$ & $48(14.7)$ & $0.95(0.20-4.40)$ & 0.94 \\
\hline \multicolumn{5}{|l|}{ Source of drinking water } \\
\hline Piping & $280(82.4)$ & $30(10.7)$ & 1 & \\
\hline Well or aqueduct & $60(17.6)$ & $20(33.3)$ & $4.17(2.16-8.04)$ & $<0.001$ \\
\hline
\end{tabular}

Our findings revealed that the prevalence of hepatitis E in Birjand, Iran, is higher than other parts of Iran and even higher than the Middle East. This discrepancy may be due to the wide geographical distribution of HEV, varying levels of exposure to the virus, and different lifestyles in different parts of Iran and the world. Moreover, differences in the population, sample size, sampling time, laboratory techniques, and serological assessment kits in the studies may be accountable for such wide discrepancy among different studies in terms of hepatitis E prevalence. Other reasons behind such a wide discrepancy in hepatitis E prevalence in different countries may be the differences in sanitation services, culture, religion, and nutritional status. Inadequate supervision on healthcare systems and lack of healthy water supply in the study setting might have been contributed to the higher prevalence rate of hepatitis $\mathrm{E}$ in our study.

The findings of the present study revealed no signifi- cant correlation between anti-HEV sero-positivity and the age of the participants. However, studies performed in Tehran (12), Khouzestan (15), and Nahavand (9) showed that hepatitis $\mathrm{E}$ was more prevalent among middle-aged individuals or individuals older than 50 . These findings indicate that age can be a risk factor for hepatitis E. It seems that exposure to HEV increases with age.

Although some studies revealed a higher seroprevalence of hepatitis $\mathrm{E}$ among men, most studies in Iran, including the present study, showed no significant correlation between gender and anti-HEV sero-positivity. It seems that gender has no significant role in developing hepatitis $\mathrm{E}(2,15,23)$.

Moreover, our findings showed that the place of residence can contribute to the development of hepatitis $\mathrm{E}$. However, some studies reported no significant difference between people who lived in urban and rural areas in terms of hepatitis E prevalence (2). We also found that 
anti-HEV sero-positivity was significantly correlated with the place of residence and the source of drinking water. An explanation for this finding is that in rural areas, people are less likely to have access to healthy drinking water. Moreover, sewage disposal systems in rural areas are not effective. The results of a study in Sudan also showed that a healthy source of water can play a significant role in preventing hepatitis $\mathrm{E}$. It is worth noting that water chlorination is not adequate for preventing hepatitis $\mathrm{E}$; rather, modern approaches are needed for effective water treatment (24). The results of a study in Indonesia also illustrated that hepatitis $\mathrm{E}$ was more prevalent among people who lived alongside rivers (24). Moreover, Gajjar et al. (2014) reported that hepatitis $\mathrm{E}$ is more prevalent in developing countries where people suffer from the shortage of healthy drinking water and environmental sanitation (25). The statistics released by the world health organization (WHO) also indicate that in countries which have ineffective sewage disposal systems, people are more at risk for developing hepatitis E. Consequently, the WHO has recommended these countries to use effective sewage disposal systems (8).

The findings of the present study also indicated a significant correlation between educational status and hepatitis $E$. This is in line with the findings of the previous studies which revealed that hepatitis $\mathrm{E}$ is less prevalent among people with higher educations. Anti-HEV positive results among people with inferior educational status can denote the role of knowledge and personal hygiene in preventing hepatitis $\mathrm{E}(15,26)$.

Another variable which was assessed in the present study was the history of blood transfusion. Transmission of infections through blood transfusion has been recently reported to be a probable route for sporadic infection in some countries (15). The results of a study in Ahvaz, Iran, also showed a higher prevalence of hepatitis E among injection drug abusers compared with inhalation drug abusers (5). However, the results of another study in Tabriz, Iran, revealed no significant correlation between blood transfusion and sero-prevalence of HEV (27). Similarly, our findings revealed no significant correlation between HEV serologic test results and the history of blood transfusion. This is in agreement with the findings of most studies in Iran even though some studies reported HEV transmission through blood transfusion in developed countries. For instance, the first cases of HEV transmission through blood transfusion were diagnosed in 2004, 2006, and 2013 in Japan, England, and Germany (6). In blood products, HEV cannot be deactivated. Moreover, screening tests by using anti-HEV IgM cannot definitely rule out the possibility of hepatitis E. Therefore, antibody screening cannot decrease the likelihood of HEV transmission. The golden standard for preventing HEV transmission among high-risk individuals is nucleotide acid test (6).

In the present study, HEV-RNA was not assessed and thus, no firm statement can be provided about the presence of HEV in the participating blood donors. In Iran, HEV screening tests are not routinely performed for blood donors. Therefore, the cost-effectiveness of performing such test for blood donors needs to be evaluated based on the epidemiology of the infection.

Although the findings of the present study show that hepatitis $\mathrm{E}$ is endemic in the studied area, yet still a large population of people in the area, are sensitive to the virus hepatitis E. In other words, in case of poor personal hygiene and environmental sanitation, a hepatitis E epidemic would be inevitable in the area. Hepatitis $E$ should be considered as one of the differential diagnosis of suspected hepatitis. On the other hand, as HEV is transmitted mainly through the fecal-oral route, promoting public health and using effective sewage disposal systems in both urban and rural areas are of great importance.

\subsection{Conclusion}

The findings of the present study indicate a higher HEV sero-prevalence compared with the previous studies, denoting the higher prevalence of hepatitis $\mathrm{E}$ in the area as well as the fact that Iran is an endemic area with regard to hepatitis E. Moreover, hepatitis E is significantly correlated with educational status, place of residence, and the source of drinking water. The chance of hepatitis $\mathrm{E}$ among people who live in rural areas is 3.56 times more compared to the chance among people who live in urban areas.

\section{Acknowledgments}

We thank the dean and the personnel of Birjand blood transfusion organization who closely collaborated with us on this research project.

\section{References}

1. Walsh SR. In: Hepatitis E virus. 8 ed. Bennett JE, Dolin R, Blaser M. J. , editors. Saunders; 2015.

2. Nazer M, Rafiei Alavi E, Hashemy J. Serologic prevalence of hepatitis E in Khoramabad City, Iran, 2009. SSU. 2010;18(5):451-60.

3. Ataei B, Nokhodian Z, Javadi A, Kasaeian N, Farajzadegan Z, Shoaei P. Seroepidemiology of Hepatitis $\mathrm{E}$ in Isfahan province: a population based study. J Med Council IR Iran. 2008;26(2):162-8.

4. Moradi A, Besharat S, Minaiifar M, Roshandel G, Tabaraii A. Seroepidemiologic assessment of Hepatitis E virus in women of reproductive age, Gorgan. Zahedan J Res Med Sci. 2010;12(1).

5. Alavi S, Ahmadi F, Ghasemirad M. Seroepidemiological study of hepatitis E virus in drug addicts in Ahvaz, Southern Iran: 2005-2006. Hepat Mon. 2008;8(4):263-6. 
6. Abravanel F, Lhomme S, Chapuy-Regaud S, Mansuy JM, Muscari F, Sallusto F, et al. Hepatitis E virus reinfections in solid-organtransplant recipients can evolve into chronic infections. J Infect Dis. 2014;209(12):1900-6. doi:10.1093/infdis/jiu032. [PubMed: 24436450].

7. Zhuang W, Ding X, Lyu C, Xiang L, Teng H, Li J. Hepatitis E virus seroprevalence among blood donors in Jiangsu Province, East China. Int J Infect Dis. 2014;26:9-11. doi: 10.1016/j.ijid.2014.04.022. [PubMed: 24981426].

8. Mohebbi R, Rostaminejad M, Ebrahim Tahaei M, Pourhoseingholi MA, Habibi M, Azimzadeh P, et al. Seroepidemiology study of hepatitis e virus infection in tehran province: A population based study. J Urmia Nurs Midwifery Faculty. 2012;9(6).

9. Taremi M, Mohammad Alizadeh AH, Ardalan A, Ansari S, Zali MR. Seroprevalence of hepatitis E in Nahavand, Islamic Republic of Iran: a population-based study. East Mediterr Health J. 2008;14(1):157-62. [PubMed: 18557463].

10. Safaar MJ, Farhadi R, Ajami A, Khalilian AR, Baba M, Shoja J. Seroepidemiology of hepatitis e virus infection in 2-25 years old subjects, sariiran. 2006

11. Ghadir MR, Jafari E, Rezvan H, Amini KS, Vaez JM, Pourshams A. Hepatitis $A$ and $E$ in the east of Golestan province. 2007

12. Aminiafshar S, Alimagham M, Gachkar L, Yousefi F, Attarchi Z. Anti hepatitis E virus seropositivity in a group of blood donors. Iranian J Public Health. 2004;33(4):53-6.

13. Rezazadeh M, Hahiloui M, Ghachkar L, Iadegari D, Kashani KM Naghdi M. study of antibody prevalence against Hepatitis E in blood donors in Hamedan, 2004. Iran J Infect Dis Trop Med. 2005;11(34):13-8.

14. Gachkar L, Taremi M, Mahmoodarabi SM, Kheradpezhouh M, Khoushbaten M, Dehkhoda R, et al. Frequency of antibodies to hepatitis E virus among male blood donors in Tabriz. 2005

15. Assarehzadegan MA, Shakerinejad G, Amini A, Rezaee SA. Seroprevalence of hepatitis $\mathrm{E}$ virus in blood donors in Khuzestan Province, southwest Iran. Int J Infect Dis. 2008;12(4):387-90. doi: 10.1016/j.ijid.2007.09.015. [PubMed: 18063401].

16. Keyvani H, Shamabadi M, Najafifard S, Hajibeigi B, Fallahian F, Alavian SM. Seroprevalence of anti-HEV and HEV RNA among volunteer blood donors and patients with Hepatitis B and C in Iran. Bangladesh Liver J 2009;1(1):34-7.

17. Christensen PB, Engle RE, Hjort C, Homburg KM, Vach W, Georgsen J, et al. Time trend of the prevalence of hepatitis E antibodies among farmers and blood donors: a potential zoonosis in Denmark. Clin Infect Dis. 2008;47(8):1026-31. doi: 10.1086/591970. [PubMed: 18781880].

18. Guo QS, Yan Q, Xiong JH, Ge SX, Shih JW, Ng MH, et al. Prevalence of hepatitis E virus in Chinese blood donors. J Clin Microbiol. 2010;48(1):317-8. doi: 10.1128/JCM.01466-09. [PubMed: 19940058].

19. Fukuda S, Sunaga J, Saito N, Fujimura K, Itoh Y, Sasaki M, et al. Prevalence of antibodies to hepatitis E virus among Japanese blood donors: identification of three blood donors infected with a genotype 3 hepatitis E virus. J Med Virol. 2004;73(4):554-61. doi: 10.1002/jmv.20125. [PubMed: 15221899].

20. Abe T, Aikawa T, Akahane Y, Arai M, Asahina Y, Atarashi Y, et al. Demographic, epidemiological, and virological characteristics of hepatitis E virus infections in Japan based on 254 human cases collected nationwide. Acta Hepatologica Japonica. 2006;47(8):384-91.

21. Cesur S, Akin K, Dogaroglu I, Birengel S, Balik I. Hepatitis A and hepatitis E seroprevalence in adults in the Ankara area. Mikrobiyoloji bulteni. 2002;36(1):79-83.

22. Chironna M, Germinario C, Lopalco PL, Carrozzini F, Barbuti S, Quarto M. Prevalence rates of viral hepatitis infections in refugee Kurds from Iraq and Turkey. Infection. 2003;31(2):70-4. doi: 10.1007/s15010-0023100-3. [PubMed: 12682810].

23. Ayoola EA, Want MA, Gadour MO, Al-Hazmi MH, Hamza MK. Hepatitis $\mathrm{E}$ virus infection in haemodialysis patients: a case-control study in Saudi Arabia. J Med Virol. 2002;66(3):329-34. [PubMed: 11793384].

24. Sedyaningsih-Mamahit ER, Larasati RP, Laras K, Sidemen A, Sukri $\mathrm{N}$, Sabaruddin N, et al. First documented outbreak of hepatitis E virus transmission in Java, Indonesia. Trans $R$ Soc Trop Med Hyg. 2002;96(4):398-404. [PubMed: 12497976].

25. Gajjar MD, Bhatnagar NM, Sonani RV, Gupta S, Patel T. Hepatitis E seroprevalence among blood donors: A pilot study from Western India. Asian J Transfus Sci. 2014;8(1):29-31. doi: 10.4103/0973-6247.126685. [PubMed: 24678170].

26. Sepanlou S, Rezvan H, Amini-Kafiabad S, Dayhim M, Merat S. A Population-based Seroepidemiological Study on Hepatitis E Virus in Iran. Middle East J Dig Dis. 2010;2(2):97-103. [PubMed: 25197520].

27. Taremi M, Khoshbaten M, Gachkar L, EhsaniArdakani M, Zali M. Hepatitis $\mathrm{E}$ virus infection in hemodialysis patients: a seroepidemiological survey in Iran. BMC Infect Dis. 2005;5:36. doi: 10.1186/1471-2334-5-36. [PubMed: 15904504]. 